\title{
Tools for Assessment of Intellectual Assets of Enterprise Based on Fuzzy Information
}

\author{
Elena Tkachenko \\ Dept. Economy and Management \\ of Enterprises and Industrial Complexes \\ St. Petersburg State University of Economics, St. Petersburg, \\ Russia \\ eletkachenko@ya.ru \\ Elena Rogova \\ St Petersburg School of Economics and Management, \\ National Research University \\ Higher School of Economics, St. Petersburg, Russia \\ erogova@hse.ru
}

\author{
Sergey Bodrunov \\ Institute for New Industrial Development, \\ St. Petersburg, Russia, \\ inir@inir.ru
}

Vladislav Klimov

JT International Ltd

St Petersburg, Russian Federation

kw-vlad@list.ru

\author{
Mariya Ganieva \\ Dept. Economy and Management of Enterprises and Industrial Complexes \\ St. Petersburg State University of Economics, St. Petersburg, Russia \\ mariya_ganieva@mail.ru
}

\begin{abstract}
This article is dedicated to the application of mathematical tools of fuzzy logic theory for the financial assessment of intellectual assets. Intellectual capital (IC) represents a special kind of capital. Intellectual assets form a potential source of company's value growth through the creation of new knowledge and its implementation in company's activities. The basis of IC is formed by speculative and cogitative power of persons, together with such factors as consumer relations, business processes, databases, brands, and IT systems. IC components shaping and developing require investments. Results measurability has always been a major problem when making investment decisions in relation to IC. For companies' financial managers, intellectual (intangible) assets are very often feebly measured up against financial results of the company. As the result of developing an analytical model, based on mathematical tools for fuzzy sets, fuzzy input information has been processed, and the results for making optimal investment decision have been obtained. The efficiency of the transfer to cloud-based computing is convincingly substantiated in the terms, interpretable by financial managers of a company.
\end{abstract} Sets

Key words - Intellectual Assets, IT, Evaluating Methods, Fuzzy

\section{INTRODUCTION}

Exploring modern evaluation methods of the development of innovative products and their application areas, the authors may also ascertain the high degree of subjectivity in the analysis that is made in adapting a particular method in a company or even in the entire industry. The specific character of innovative projects makes it difficult to carry out their evaluation. In this regard, the topical issue is the improvement mathematical of apparatus of evaluation methods, as well as that of calculation and analytical base of projects analysis. The most common classical models proved to be insufficiently effective, because they had several internal restrictions, determining the hard boundaries for their application in relation to innovative projects. The following two approaches are the most evident and suitable ones for company's intellectual capital management needs: strategy maps, developed by Kaplan and Norton [14] on the basis of Balanced Scorecard, and IC Navigator (Skandia Navigator), based on the research that Roos et al. [27] had performed during their work at Skandia. These approaches are defined by the expert analytical qualitative model of intellectual assets assessment. They are sufficient for strategic management, but do not meet the objectives of financial management. When managers encounter the problem of evaluating the effectiveness of the projects, related to investing into such assets as information technologies, just qualitative methods of assessment are not enough in order to make rational decisions. The use of traditional methods of investment analysis also does not yield the desired result, since input information, when developing such projects, is fuzzy in nature, thus resulting in high ambiguity of project's results.

It is obvious that the evaluation of such projects requires both specific methods, considering a set of attributes of the object under analysis, and refinement of mathematical models, used for the calculation of metrics and parameters for further analysis. Thus, it seems prospective to implement mathematical logic, which, first, considers the subjective character of evaluations provided by experts; second, has a built-in mechanism of training and adaptation to the requirements made in specific conditions; and, third, may be equally successful in using diverse input and output parameters. One of the developments of this approach is fuzzy logic application to decision-making on capital investments [6, $16,37]$ 


\section{LITERATURE REVIEW}

The idea of application of fuzzy logic to the tasks of business analysis and investment decisions has become popular in recent years. The growth of turbulence in the markets affects projects and makes them uncertain in regard to key efficiency parameters. This consideration limits the classical approach to investment analysis and requires new tools. The major streams of fuzzy logic implementation in business analysis are the following.

The improvement of multi-criteria models, like AHP and PROMEETE [1, 7, 23, 32, 38]

The implementation of fuzzy logic in the analysis of projects [5, 12, 13, 17 19, 24, 37]

The problem of IT-projects evaluation is the large number of inputs and the lack of quantified information on them. Gunasekaran et al. [11] have analyzed IT-projects evaluation, including analysis of material and intangible benefits. They specify three main approaches: economic, strategic and analytical ones.

Qualitative (heuristic) methods of project evaluation suggest calculating not only purely financial and investment metrics, but also determining what strategic objectives of a company (or specific IT-department) may be achieved with the implementation of the project. The advantage of these methods is also the attempt to enhance quantitative analysis with qualitative evaluations. Consequently, the use of qualitative methods helps specialists to evaluate not only direct (explicit) effects of the project, but also to take into account implicit effects. Moreover, they may set specific weight coefficients for each indicator calculated for the project, identifying its importance for achieving the specified goals. This becomes important when one talks about a separate project and a portfolio of projects that directly/indirectly affect the success of a company's overall strategy. The main disadvantage of these methods lies in the fact that a company needs to develop its own detailed system of indicators and implement it in all of its divisions throughout the added value chain. Another disadvantage is that the leaders of working groups involved in the analysis of a specific project may subjectively determine the metric.

Probability (stochastic) methods allow evaluating risk probability (threat or opportunity), using statistical and mathematical models. To build such models, it is required to have occurrence statistics of the considered events in the analytical report. The main difficulty of using such models is, first, a sophisticated mathematical apparatus; second, the availability of probability statistics of specific risks that may be found in the reports of the companies, engaged in the analysis of specific market sectors, or by applying one of the mathematical models, or by expertise (if experts have the respective experience).

The overview of evaluation methods is represented in Figure 1.

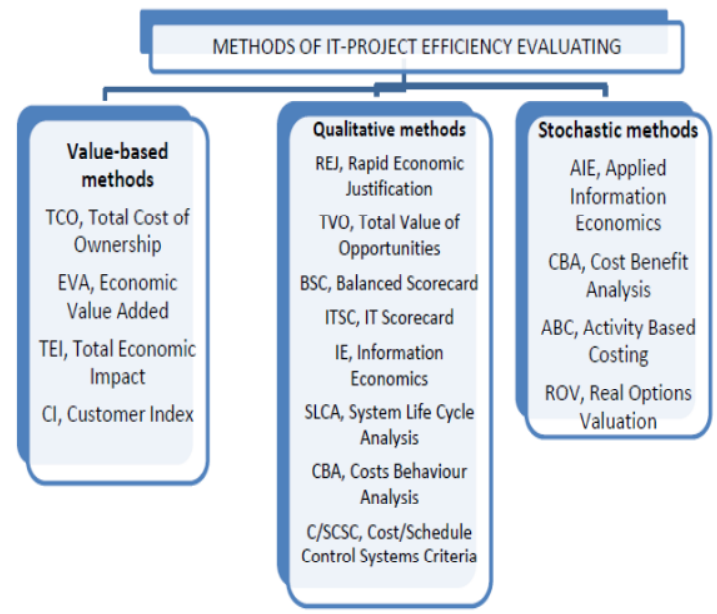

Fig. 1. Evaluation methods concerning the economic efficiency of ITprojects

Let us consider some of the above-mentioned methods and analyze the possibilities of their use when justifying investments in intellectual assets.

\section{Economic approach: Method of net present value (NPV)}

The investment management theory considers the net present value method as the best one that reflects the impact of an investment project on the market value of a company. First, it takes into account the time value of money and, consequently, it is valid from the theoretical viewpoint. Second, the NPV is determined solely by the size of the generated net cash flows and the opportunity cost of capital. Third, the NPV is an additive criterion and thus allows evaluating the efficiency of combined investments. However, this theoretically impeccable criterion may not always be used in practice, especially in the evaluation of technological innovations. There are four main problems, associated with the use of the net present value for the evaluation of investments in new technologies.

1. Accuracy of evaluation concerning the cash flows, generated by the project.

2. NPV criterion is "passive" in relation to strategic managerial decisions.

3. According to the existing opinion, it is impossible to take account of risk factor using the net present value.

4. One of the most important problems in using the net present value criterion is the choice of a discount rate.

Thus, this method has essential restrictions and does not allow estimating the intangible effects generated by IT project.

Strategic approach: Economic Value Added (EVA).

This indicator introduced by [29, 30] has become evermore widespread over the past years. EVA measures the difference between the return on invested capital and the company's cost of capital; this difference should be positive.

The advantages of EVA are the simplicity of understanding and easy calculation, which provides ample opportunities for its application. However, EVA, like NPV, is determined by taking into account all investments in the 
project and requires accuracy of calculations. Moreover, this indicator does not regard quality characteristics and effects. These drawbacks led to the wide-spread application of complex project evaluation systems with the involvement of intellectual assets, such as Balanced Scorecard [14]. This system is considering the company's performance from several points of view.

1) How do consumers evaluate a company (consumer aspect)? 2) What processes can provide a company with exclusive competitive advantages (internal aspect)? 3) How to ensure the further company's improvement (innovation and learning aspect)? 4) How do shareholders evaluate a company (financial aspect)? For each aspect, goals and indicators that characterize their achievement, as well as tasks and measures for their implementation, are given. At the same time, the set of indicators, used to evaluate a project, should include indicators from each group.

The significant negative aspect of applying the concept of balanced scorecard to individual projects is that it is not always possible to group the indicators of an investment project in accordance with BSC classic methodology. Thus, the above-mentioned methods for evaluating the return on investments in new technologies have disadvantages, limiting their applicability. In particular, these methods overlook the strategic value of a project (it can be taken into account in the criteria of the balanced scorecard, but this method can hardly be applied to individual projects).

Analytic Approach: Rapid Economic Justification Model as the method of measuring the effectiveness of intellectual capital management projects

The method is developed by Mascarella [20] and Microsoft Corporation. The entire project analysis process on the base of REJ model can be divided into five successive stages, each of them requiring certain incoming documents (information) and having a set of resulting documents, some of which are transferred to the next stage for further elaboration or included in the final study report of the project efficiency:

- evaluation of the current state of business;

- $\quad$ solution development (proprietary solution, or the choice of a supplier and technology);

- determination and calculation (quantitative evaluation) or description (qualitative evaluation) of benefits and costs of the project;

- risk assessment;

- calculation of financial indicators;

- drawing up and signing a memorandum and a statement on the project appeal.

One may also specify a proposed sequence map concerning stages with specific step actions, which should be performed by working groups (experts), involved in the analytical work at a particular stage. Some functions, performed at certain stages, coincide, and show both close relationship between the stages and the fact that the number of functions (for example, risk assessment) are relevant for the majority of stages.
Klimov [15] proposes a solution to improve the quality of decision support in intellectual assets management, proceeding from fuzzy input information. The use of fuzzy sets allows overcoming the limitation of a classical model.

The introduction of fuzzy sets as an alternative to classical Aristotelian sets is the attempt to describe fuzzy input information in mathematical formulas. Thus, the classic approach suggests that the degree of membership of a value to a set is defined as $\mu_{A}(X)=[0 ; 1]$. A fuzzy set accepts the existence of intermediate values, $A=\{x, \mu \cdot A(x)\}$, where $x \in X$.

Zadeh (1965) is the founder of the theory of fuzzy sets. Starting from this moment, one can distinguish three key stages of fuzzy sets development, in the course of which the principles of fuzzy sets and the methods of their application were described $[4,9]$; practical relevance and effectiveness of fuzzy logic models were proved [6, 16]; and, finally, active dissemination of fuzzy logic in various sectors and popularization of basic algorithms was performed [18, 31].

To overcome the limitations of the traditional binary model, Zadeh [35] proposes an introduction of the so-called "linguistic variable", which expresses the semantic value of the indicator. The analysis of the linguistic variable makes it possible to change clear mathematical models into fuzzy ones. However, the choice and the formation of the membership function represent the chief difficulty and the most subjective stage in working with fuzzy sets. Most often, in the construction of membership, scientists use typical functions triangular, trapezoidal, S-function, $\pi$-function, Z-function, sigma-function, Gauss function, Bell function, etc. The authors will not dwell upon each formula within this article, we will only mention that the ones that gained wide acceptance are a trapezoidal and $S(Z)$ function (if the effect of an argument on the function is simple) and Gauss and Bell functions (if the effect is complex).

When the membership function is completed, it is necessary to form a fuzzy inference machine, that is, a proprietary set of rules that the model will use for the processing of incoming information. For this purpose, an expert or a group of experts make a list of implicative logical statements that define cause-and-effect relationship. Logical connection may be expressed by conjunction or disjunction of functions, that is, they may be combined by logical AND or OR, implicative ligaments are also defined.

The final stage of the modeling is to transfer fuzzy results into a clear value (for that, a membership function, built for the output parameter, is used). Thus, based on our assertions and the membership functions constructed, we get a clear value generated by the system, which, in fact, is identified as the gravity center of the figure obtained for the output parameter.

\section{RESEARCH METHODOLOGY}

The research is based on the development and the application of the IT-project evaluation model at the above- 
described rationale. The financial model operates with data, obtained by the expertise of the project that has been implemented by the Russian branch of Japan Tobacco International (JTI). The objective is to compare the results that were obtained on the base of the traditional approach, used by the company (total cost of ownership, NPV and payback period evaluation), and the approach based on the fuzzy logic and considering material and intangible benefits of the project.

To identify intangible benefits, we used the managers' survey. We asked them to describe the expected project effects in such areas as the cost reduction in IT-departments, the concentration on the major competences due to the possibility to outsource the exploitation activities, the growth of flexibility and scale effects, the IT-infrastructure use improvements.

All these parameters were assessed using the 5-grade scale. The obtained scale became a foundation for constructing the linguistic variables that were used in the fuzzy model development.

\section{THE EXAMPLE OF APPLICATION OF THE FUZZY SET APPROACH: THE EVALUATION OF TRANSITION FROM THE IT-SYSTEMS TO CLOUD COMPUTING PROJECT}

Let us consider a decision-making process, based on the example of justification of the viability of making the transition to cloud computing. The example is based on the JTI Corporation, Russian branch. The shift from standard technologies to cloud computing provides the following technological and managerial benefits for the business.

Cost-saving at all levels of the IT departments, associated with the implementation, customization, support, and update of the system.

Focusing on key activities.

Scalability and flexibility of the solution.

Relative simplicity of integration (migration) and operation.

Quality improvement of the services provided.

Automation level improvement.

Portability of the technology.

Optimization of IT infrastructure resources.

With the list of benefits from the use of cloud technology, we have two alternative ways of analysis that can be implemented as the basis of fuzzy set approach:

1) To consider each of the following benefits as the factor, influencing the final indicator - the profitability of the project. In this case, the above-stated positive effects are the input parameters, while the profitability of the project is the output parameter. The main advantage of this analysis will be the speed of its implementation, as well as a clear determination of the cause-and-effect relationships (described by fuzzy algorithm). However, there is one disadvantage - the approach gives rather subjective and approximate evaluation, because each expert needs to make a preliminary assessment of the effects based on a defined scale (for example, to evaluate the scalability of new technology based on a 10-point rating scale), and that will reflect the expert's personal attitude to the subject of the analysis.

2) To consider every effect independently, and to create a fuzzy handling mechanism for each one, and only then to combine them into one input parameter for a new fuzzy analysis of the final result - the profitability of the project as a whole. From the standpoint of fuzzy logic toolkit, this means creating the following algorithm:

a) to select one of the effects of the project implementation and to analyze it: to define the factors influencing its success; to define links; to create a fuzzy handling mechanism and to evaluate the effect by means of fuzzy logic

b)

to repeat the procedure for each effect. Thus, we must get the i-e number of fuzzy logic mechanisms, each having its own set of input parameters and output parameter that benefit from the implementation of the project;

c) to consider the claimed effects of implementation of the project as the input parameters for new fuzzy logic mechanisms that provide the evaluation and expression of the metrics of interest at the output (profitability, margin, cash flow value, etc.)

The following advantages of such evaluation approach are worth noting: it minimizes subjective evaluation to the greatest possible extent; each step of the analysis gives us the possibility to create a local fuzzy analysis machine which is independent of others. Therefore, each such mechanism has its own set of parameters that it uses, and its own output parameter, which is the input parameter for the final fuzzy logic machine (Fig. 2). The obvious disadvantage of this approach is that during the analysis it will require a large number of resources, including analytical resources, the demand for which will grow in geometric progression: the larger the number of the identified effects and the factors affecting them, the more fuzzy-mechanisms will have to be created, and the more complicated structure they will have.

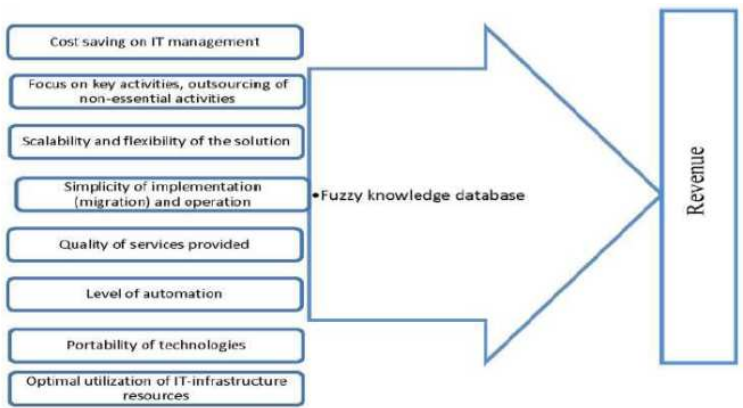

Fig. 2. Fuzzy logic model for efficiency evaluation for the transition to cloud computing

The next step in the creation of the fuzzy logic model is the study of linguistic and fuzzy variables. These are the key concepts of fuzzy logic theory, and their definition allows us to move from crisp values to fuzzy ones, from a binary language to a semantic one. For each of the given input and output parameters, we define a linguistic variable, and then the associated membership function. However, before creating them, it is worth noting the input specific features of the 
project. The project, which we analyze using fuzzy logic, is an innovative one, and it describes innovation in the field of information technology; consequently, it is characterized by the parameters that have no analogues for the evaluation. Moreover, some of these parameters are difficult to evaluate on the base on any scale. Thus, we see the problem - the proposed assessment parameters that will be used as input parameters for the model can either be evaluated based on a predetermined scale of metrics (in this case, such evaluation will be subjective and rather stochastic) or characterized by qualitative evaluation. That is one of the major problems that arise when we consider the innovation projects, and that, with varying degrees of success, are solved by the use of one or other evaluation models.

Within the framework of the theory of fuzzy sets and its application, we offer the following approach: to eliminate the requirement of input parameters with a set crisp value. It is traditionally considered that the mechanism of fuzzy logic receives a set number of parameters with set crisp values as an input, and it is subsequently subject to further fuzzification, that is a correlation of crisp value with semantic term value. We suggest the following approach to overcome this limitation: thus, at the input, the mechanism will be able to accept the parameters determined quantitatively (crisp evaluation) and qualitatively (fuzzy evaluation). Consequently, the control of input parameters will be more complicated, because it will be necessary to determine not only the factor itself, fuzzy variable and linguistic variable, but also to make a correction for the value that has been assigned to the factor, either quantitative or qualitative. On the other hand, of even greater importance is the fact that we get universal flexibility not limited to the need to measure this parameter (a scale will be needed in the process of the creating membership functions for the variable, but this task is much easier than assigning a crisp parameter that is difficult to evaluate).

Such flexibility allows any expert to define the input pattern on his/her own, depending on the value, meaning, complexity, and the specificity of the assessment of input features. Thus, the fuzzy logic model provides the value of the total revenue that a company will receive if the project is implemented. In order to determine the revenue, which a company will receive at each stage of project implementation, we distribute its total value equivalently into shares. Thus, the implementation of the project takes 10 quarters followed by the 2 quarters of the launch of new system operation (start, intensive support, and elimination of critical mistakes, more accurate definition of specifications and operational conditions etc.). It is clear that such stages as planning, definition of system requirements, configuration, testing, and new solution deployment in different regions generate no revenue, since the system, in fact, is not in efficient operation. Naturally, a company does not receive economic benefits from it. The system launch (the $1^{\text {st }}$ quarter of 2013) may be considered as the beginning of the system's work for the achievement of business objectives, that is, the beginning of assessment of the revenue received from it. Thereby, we have 10 quarters, during which we design and configure the solutions, the revenue during which will be equal to zero, and 2 quarters after the system start up, which begin to yield positive economic results. In addition, we extend the time horizon of the analysis and directly consider not only the time of project implementation, but also the following 5 years (20 quarters) as the most effective from the point of view of system operation. Thus, we are able to analyze not only the scheme of revenue receipts and expenditures associated with the project implementation, but also a number of other economic indicators, the calculation of which would have been objectively impossible, if we had confined ourselves exclusively to the period of the project implementation (e.g. payback period, profitability index etc.). This is because ITprojects, especially those ones that offer the implementation/modernization of a complex system, require commitment of considerable resources, while their efficiency (not only economic) is being introduced over quite a long period of time, and this should be analyzed in order to get comprehensive and overall assessment.

Therefore, we shall use our fuzzy data manipulation apparatus only in the course of these 5 years, during which the operation of a new system of business analytics, migrated to the cloud platform, forms the flows of means (revenues). Unfortunately, it is impossible to present graphically the finite surface, which is formed based on the geometry of the membership functions and the established judgments from the rule base, since it has to be built in 12 and 9-dimensional space, respectively (the number of input and output parameters). This cannot be done on a two-dimensional subspace. However, this does not make the work of apparatus, based on working with the fuzzy sets, less efficient or illustrative. The best data representation in this case will be tabular presentation (table 1).

TABLE I. OUTPUT PARAMETERS OF THE PROJECT. THE NAME OF A LINGUISTIC VARIABLE: 'THE OPTIMALITY OF IT-INFRASTRUCTURE RESOURCES UTILIZATION' SET OF PRECISE VALUES: [0; 100] NUMBER OF THE BASIC TERMSET ELEMENTS: 3

\begin{tabular}{|c|c|c|}
\hline $\begin{array}{c}\text { Set of fuzzy } \\
\text { values }\end{array}$ & $\begin{array}{c}\text { Type of a } \\
\text { membership function }\end{array}$ & Input features \\
\hline low & Z-function & {$[4 ; 40]$} \\
\hline medium & triangular & {$[20 ; 60 ; 75]$} \\
\hline high & S-function & {$[65 ; 100]$} \\
\hline
\end{tabular}

So, we have completed the construction of the valuation model of effects (in this context - benefits) of the project implementation, which provides data for the planned levels of annual revenue. Now, if we input the parameters' values in qualitative or quantitative terms, which correspond to their status during each interval of time, we will get the following results (in this case, we do not consider the first two years from the beginning of the development of the solution, for its development and implementation do not generate positive cash flows. On the contrary, it is an extremely costly period, which may be considered as the period of capital spending) (table 2): 
TABLE II. PLANNED RECEIPTS AFTER PUTTING THE PROJECT INTO PRODUCTIVE OPERATION

\begin{tabular}{|c|c|}
\hline Year & $\begin{array}{c}\text { Planned receipts, millions of US } \\
\text { dollars }\end{array}$ \\
\hline 2013 & $6,024.24$ \\
\hline 2014 & $7,930.13$ \\
\hline 2015 & $7,523.50$ \\
\hline 2016 & $7,572.39$ \\
\hline 2017 & $7,115.81$ \\
\hline
\end{tabular}

Accordingly, the fuzzy input information was processed. This information was defined by a set of quantitative and qualitative parameters, which are included in the quantum model, and it was processed within the framework of a developed model. The output information obtained transmits fuzzy output parameters into financial indicators, based on which any weighted management decision may be taken.

\section{CONCLUSION}

The key driver of managerial decision-making at the corporate level is the creation and an increase of a company's value. The approach to the evaluation of innovative projects, based upon the fuzzy logic, helps to expand value-based evaluation at the horizon of future strategic outputs, generated by the intellectual capital, and to take into consideration not only explicit qualitative indicators but also tacit and sometimes immeasurable advantages that would be created in the future and are not evident at the current viewpoint.

The theoretical contribution of the paper is the development of the model of project evaluation that is implementing the fuzzy apparatus for the better understanding and involvement of intellectual capital investments into decision-making. As the example has revealed, the model also has a practical implementation.

\section{References}

[1] L. Abdullah, Fuzzy multi criteria decision making and its applications, pp. A brief review of category, Procedia - Social and Behavioral Sciences, 97, pp. $131-136,2013$.

[2] E. Abrahamson, L. Rosenkopf, When Do Bandwagon Diffusions Roll? How Far Do They Go? When Do They Roll Backwards? A Computer Simulation, Academy of Management Conference, Best Paper Proceedings, Northwestern University, Evanston, IL, pp. 155-159, 1990.

[3] M.F. Bass, A New Product Growth For Model Consumer Durables, Management Science, 15 (5), pp. 215-227, 1969.

[4] R.E. Bellman, L.A. Zadeh, Decision-Making in a Fuzzy Environment, Management Science, 17, pp. 141-164, 1970.

[5] V. Bezděk, Using fuzzy logic in business, Procedia - Social and Behavioral Sciences, 124, pp. 371-380, 2014.

[6] P. Cheeseman, Probability versus Fuzzy Reasoning, Uncertainty in Artificial Intelligence, North-Holland, Amsterdam, pp. 85-102, 1986.

[7] T.-Y. Chou, S.T. Chou, G-H. Tzeng, Evaluating IT/IS investments, pp. A fuzzy multi-criteria decision model approach, European Journal of Operational Research, 173 (3), pp. 1026-1046, 2006.

[8] M. Dodgson, R. Rothwell, The Handbook of Industrial Innovation, Edward Elgar, Brookfield, 1994.

[9] D. Dubois, H. Prade, R.R. Yager, Readings in Fuzzy Sets for Intelligent Systems, Morgan Kaufmann, San Francisco,CA, 1993.
[10] R.A. Fatkhutdinov, Innovation management, pp. The textbook for higher education institutions. 5th ed, Piter, St.-Petersburg, 2005.

[11] A. Gunasekaran, P.E.D. Love, F. Rahimi, R. Miele, A model for investment justification in information technology projects, International Journal of Information Management, 21 (5), pp. 349-364, 2001.

[12] M. Iluza, A. Shtubb, Simulation Based Planning of the Fuzzy Front End Stage of a Project, Procedia CIRP, 36, pp. 106-110, 2015.

[13] M. Ingle, M. Atique, S.O. Dahad, Risk Analysis Using Fuzzy Logic, International Journal of Advances in Engineering and Technology, 2(3), pp. 96-99, 2011.

[14] R.S. Kaplan, D.P. Norton, The balanced scorecard - Measures that drive performance, Harvard Business Review, 70 (1), pp. 71-79, 1992.

[15] V.V. Klimov, Use of fuzzy logic for an assessment of risks of implementation of projects in the sphere of information technologies, News of St. Petersburg University of Economics and Finance, 1(61), pp. 89-92, 2010.

[16] B. Kosko, Fuzzy Systems as Universal Approximators. In, pp. Proceedings of IEEE International Conference on Fuzzy Systems, San Diego, pp. 1153-1162, 1992.

[17] G. Lesinski, 2015, Application of Value Focused Thinking and Fuzzy Systems to Assess System Architecture, Procedia Computer Science 61, pp. 168-175.

[18] E.H. Mamdani, B.R. Gaines, Fuzzy Reasoning and its Applications, London, Academic Press, 1981.

[19] P. Mariusa, D. Trandabatb, A. Trandabatc, Assessment of Corporate Environmental Performance Based on Fuzzy Approach, APCBEE Procedia, 5, pp. 368-372, 2013.

[20] G. Mascarella, Rapid Economic Justification, pp. Enterprise Edition, pp. A Step-by-Step Guide to Optimizing IT Investments that Forge Alliances Between IT and Business, Microsoft Publication, Redmond, WA, 2005. URL http://mbstrauch.com/wpcontent/uploads/2013/03/Book_MSFT_REJ_Enterprise_.pdf, access date, pp. 09 January 2016.

[21] G.O. Mensch, Innovation Management in Diversified Corporations, pp. Problems of Organization, The Journal of Science Policy and Research Management, 2 (4), pp. 487, 1987.

[22] D.F. Midgley, G.R. Dowling, Innovativeness, pp. the concept and its measurement, Journal of Consumer Research, 4, pp. 229-242, 1978.

[23] J.Y. Pak, V.V. Thai, G.T. Yeo, Fuzzy MCDM Approach for Evaluating Intangible Resources Affecting Port Service Quality, Asian Journal of Shipping and Logistics, 31(4), pp. 459-468, 2015.

[24] L. Papea, K. Giammarcob, J. Colombic, C. Daglia, N. Kilicay-Ergin, G. Reboviche, A fuzzy evaluation method for system of systems metaarchitectures, Procedia Computer Science, 16, pp. 245 - 254, 2013.

[25] V.V. Platonov, Approaches to the financial evaluation of projects participating in an open innovation platform, St. Petersburg, 2009.

[26] E. Rogova, Formation and Implementation of a Technological Transfer Mechanism. Publishing house SPbSUEF, St.Petersburg, 2005.

[27] J. Roos, G. Roos, N.C. Dragonetti, L. Edvinsson, Intellectual Capital, pp. Navigating the New Business Landscape, Macmillan Business, London, 1997.

[28] J.A. Schumpeter, R. Opie, The theory of economic development, pp. an inquiry into profits, capital, credit, interest, and the business cycle, Transaction Books, New Brunswick, New Jersey. Translated from the 1911 original German, Theorie der wirtschaftlichen Entwicklung, 1983.

[29] J. Stern, Corporate Governance, EVA, and Shareholder Value, Journal of Applied Corporate Finance, 16 (2-3), pp. 91-99, 2004.

[30] G. B. Stewart, EVA ${ }^{\mathrm{TM}}$, Fast and Fantasy, Journal of Applied Corporate Finance, 7 (2), pp. 71-84, 1994.

[31] M. Sugeno, T.A. Yasukawa, Fuzzy-Logic-Based Approach to Qualitative Modeling, IEEE Transactions on Fuzzy Systems, 1 (1), pp. 7-31, 1993.

[32] N. Thomaidis, N. Nikitakos, G.D. Dounias, The Evaluation Of Information Technology Projects, A Fuzzy Multicriteria DecisionMaking Approach, International Journal of Information Technologies Decision Making, 05 (89), 2006, DOI, pp. $10.1142 / \mathrm{S} 0219622006001897$ 
[33] P. Trott, Innovation Management and New Product Development, 2nd ed, Pearson Education Limited, Gosport, 2002.

[34] E.A. Utkin, N.I. Morozova, G.I. Morozova, Innovation management, AKALIS, Moscow, 1996.

[35] L.A. Zadeh, Fuzzy Sets, Information and Control, 8 (3), pp. 338-353. , 1965

[36] P.N. Zavlin, A.E. Kazantsev, L.E. Mindeli, Innovation management, pp. Handbook, Nauka, St. Petersburg, 1997.
[37] X. Zhang, Venture Capital Investment Selection Decision-making Base on Fuzzy Theory, Physics Procedia 25, pp. 1369 - 1375, 2012.

[38] Y.Zhu, H. Lei, Fuzzy AHP Analysis on Enterprises' Independent Innovation Capability Evaluation, Physics Procedia, 24, pp. 1285 1291, 2012. 
